\title{
Solanine-induced reactive oxygen species inhibit the growth of human hepatocellular carcinoma HepG2 cells
}

\author{
XUE-QIN MENG, WEI ZHANG, FENG ZHANG, SHENG-YONG YIN, \\ HAI-YANG XIE, LIN ZHOU and SHU-SEN ZHENG \\ Key Lab of Combined Multi-Organ Transplantation, Ministry of Public Health, The First Affiliated Hospital, \\ Zhejiang University School of Medicine, Hangzhou, Zhejiang 310003, P.R. China
}

Received December 8, 2014; Accepted December 3, 2015

DOI: $10.3892 / \mathrm{ol} .2016 .4167$

\begin{abstract}
The aim of the present study was to investigate the effect of solanine on promoting human hepatocellular carcinoma HepG2 cells to produce reactive oxygen species (ROS), and the molecular mechanisms leading to tumor cell apoptosis. Solanine was administered to HepG 2 cells in vitro. A selection of probes targeting various cellular localizations of ROS were used to detect ROS expression using flow cytometry. The expression levels of apoptosis-associated proteins, including apoptosis signal-regulating kinase 1 (ASK1) and thioredoxin binding protein 2 (TBP-2), and proliferation-associated proteins, including histone deacetylase 1 (HDAC1), were detected using western blotting. The percentage of cells undergoing apoptosis was measured using an Annexin V-fluorescein isothiocyanate/propidium iodide assay, and cell morphology was examined using Wright's stain followed by inverted microscopy analysis. ROS detection probes 2',7'-dichlorofluorescin diacetate and dihydrorhodamine 123 identified that abundant ROS, including hydroxyl radical $\left(\mathrm{OH}^{-}\right)$and hydrogen peroxide $\left(\mathrm{H}_{2} \mathrm{O}_{2}\right)$, were produced in the cytoplasm and mitochondria of the solanine-treated HepG2 cells compared with the control cells $(\mathrm{P}<0.05)$. Superoxide anion specific probes dihydroethidium and MitoSOX ${ }^{\mathrm{TM}}$ demonstrated that there were no significant alterations in the HepG2 cells following solanine treatment compared with the control cells $(\mathrm{P}>0.05)$. Western blotting results revealed that solanine upregulated the expression levels of ASK1 and TBP-2 and enhanced their kinase activities, whereas solanine decreased the expression level of the proliferation-associated protein, HDAC1. The cell apoptotic rate was significantly increased $(\mathrm{P}<0.0001)$ in the
\end{abstract}

Correspondence to: Professor Shu-Sen Zheng, Key Lab of Combined Multi-Organ Transplantation, Ministry of Public Health, The First Affiliated Hospital, Zhejiang University School of Medicine, 79 Qingchun Road, Hangzhou, Zhejiang 310003, P.R. China

E-mail: shusenzheng@zju.edu.cn

Key words: hepatocellular carcinoma, solanine, reactive oxygen species, apoptosis signal-regulating kinase 1, thioredoxin binding protein 2 , histone deacetylase 1 solanine-treated HepG2 cells compared with the control cells. $(\mathrm{P}<0.05)$. Overall, the study indicated that solanine induces HepG2 cells to produce ROS, mainly $\mathrm{OH}^{-}$and $\mathrm{H}_{2} \mathrm{O}_{2}$, in a mitochondria-dependent and -independent manner. In addition, solanine stimulates the expression of ASK1 and TBP-2, and their kinase activities, but inhibits the expression of proliferation-associated proteins, such as HDAC1, thus contributing to HepG2 cell apoptosis.

\section{Introduction}

Hepatocellular carcinoma (HCC) is a significant worldwide health issue. In developing countries, the overall incidence of HCC remains extremely high, and in the majority of developed countries, the incidence of HCC has steadily increased; this is due to the spread of hepatitis B and C $(1,2)$. Currently, the main treatment strategies for patients with HCC consist of surgical resection, liver transplantation and local ablation therapies (3). A large number of the patients diagnosed with advanced-stage HCC may only be treated with palliative care $(2,4)$, as there is no available effective palliative chemotherapy. Therefore, the prognosis of patients with advanced-stage HCC is poor (5). Consequently, novel effective medications for the treatment of $\mathrm{HCC}$ are required. Recently, the study into treatments for HCC has focused on natural products, which are pharmacologically effective, with little toxicity and few side effects.

Solanine is mainly located in the tuber of the potato plant (Solanum tuberosum L.) and in the whole nightshade plant (S. nigrum L.), which belong to the Solanaceae family (6-10). Solanine expression is relatively high in the green peel and the sprouts of a potato tuber and is the main toxic substance produced (11), with a molecular formula of $\mathrm{C}_{45} \mathrm{H}_{73} \mathrm{NO}_{15}(12,13)$. The whole nightshade plant contains numerous steroid alkaloids, including solamargine, solasonine, solanine and saponin, and may be used for antitumor therapeutics, as it has a clear inhibitory effect on tumor growth in animal models and a toxic effect on tumor cells $(14,15)$. The ethanol extract of nightshade is able to inhibit the growth of breast cancer and induce apoptosis in tumor cells (16).

Previous studies have demonstrated that solanine affects tumor growth through several possible biological mechanisms. An et al (17) revealed that solanine significantly reduces the membrane fluidity and protein levels of tumor cells in xenograft 
mice with hepatoma $\mathrm{H} 22$ tumors. In addition, solanine effectively reduced the sialic acid level and membrane closing ability of the tumor cells. A previous study demonstrated that the mechanism by which solanine induces human hepatocellular carcinoma HepG2 cells to undergo apoptosis appeared to be mediated by the inhibition of B-cell lymphoma-2 expression (18). Furthermore, solanine has been demonstrated to increase the permeability of the mitochondrial membrane, which leads to the release of apoptosis-associated proteins and inner mitochondrial calcium ions, resulting in tumor cell apoptosis through the mitochondrial pathway $(19,20)$. Eom et al (21) reported that the berberine-induced apoptosis of human glioblastoma cells was mediated by reactive oxygen species (ROS) and mitochondrial dysfunction, which indicates that ROS are important in cellular apoptosis. The present study investigated the molecular mechanism of solanine-induced HCC cell apoptosis, in particular ROS that are involved in the apoptotic pathway of tumor cells. The present study cultured HepG2 cells treated with solanine in vitro, and subsequently monitored the production of ROS from the mitochondria and cytoplasm of HepG2 cells using probes for ROS.

\section{Materials and methods}

Cells and solanine treatment. The human hepatocellular carcinoma HepG2 cell line was provided by the Shanghai Cancer Institute (Shanghai, China). The HepG2 cells were cultured in HyClone $^{\mathrm{TM}}$ Dulbecco's modified Eagle's medium (GE Healthcare Life Sciences, Logan, UT, USA) supplemented with $10 \%$ inactivated fetal bovine serum (Sigma-Aldrich, St. Louis, MO, USA) in a $5 \% \mathrm{CO}_{2}$ Forma $^{\mathrm{TM}}$ humidified incubator (Thermo Fisher Scientific, Inc., Waltham, MA, USA ) at $37^{\circ} \mathrm{C}$. The cells were seeded onto a 6 -well plate $\left(4 \times 10^{4}\right.$ cells/well), allowed to adhere overnight, and subsequently treated with solanine (95\% mass fraction; Sigma-Aldrich) with a final concentration of $2 \mathrm{mg} / \mathrm{ml}$. The cells were incubated for 24-48 h. A negative control [dimethyl sulfoxide (DMSO); Sangon Biotech Co., Ltd., Shanghai, China] and a positive control (camptothecin, $0.5 \mathrm{mg} / \mathrm{ml}$; Sigma-Aldrich) were used.

ROS detection using flow cytometry. Various concentrations of hydrogen peroxide $\left(\mathrm{H}_{2} \mathrm{O}_{2} ; 0.5 \mathrm{mM}\right.$; Sinopharm Chemical Reagent Co., Ltd., Shanghai, China) was added to each well, followed by an incubation period of $30 \mathrm{~min}$ prior to uniformly blending the cells in each well. The cells were washed twice with phosphate-buffered saline (PBS) and the Invitrogen ${ }^{\mathrm{TM}}$ fluorescent probes (Thermo Fisher Scientific, Inc.), 2',7'-dichlorofluorescin diacetate (DCFDA), dihydrorhodamine 123 (DHR 123), dihydroethidium (DHE) and MitoSOX ${ }^{\mathrm{TM}}$ (MITSOX; a mitochondrial superoxide probe), were added to the cells according to the manufacturer's protocols. The cells were incubated at $37^{\circ} \mathrm{C}$ for $30 \mathrm{~min}$ in the dark. Subsequently, the cells were washed twice with PBS and analyzed using flow cytometry (BD LSR II Flow Cytometer; BD Biosciences, San Jose, CA, USA).

Western blotting. In total, $48 \mathrm{~h}$ after solanine treatment, total protein was extracted from the HepG2 cells using RIPA Lysis and Extraction Buffer (Thermo Fisher Scientific, Inc.), which contained proteinase and phosphatase inhibitors, at $4^{\circ} \mathrm{C}$ for
$30 \mathrm{~min}$. The cell lysates were centrifuged at $12,000 \mathrm{x} \mathrm{g}$ for $20 \mathrm{~min}$ at $4^{\circ} \mathrm{C}$. The protein concentrations of the resulting supernatants were determined using a Bicinchoninic Acid Protein Assay kit (Beyotime Institute of Biotechnology, Shanghai, China). The supernatants were mixed with $5 \mathrm{X}$ sodium dodecyl sulfate (SDS) loading buffer (Thermo Fisher Scientific, Inc.) and heated at $95^{\circ} \mathrm{C}$ for $5 \mathrm{~min}$. In total, $40 \mu \mathrm{g}$ of protein was loaded onto and separated by $12 \%$ Tris-Glycine SDS gel (Sangon Biotech Co.,Ltd.), which was subsequently transferred onto polyvinylidene fluoride membranes (pore size, $0.22 \mu \mathrm{m}$; Merck Millipore, Darmstadt, Germany). The membranes were blocked with $5 \%$ skimmed milk in Tris-buffered saline and Tween 20 (Sangon Biotech Co., Ltd.), and incubated overnight with primary antibodies. The primary antibodies were as follows: Anti-apoptosis signal-regulating kinase 1 (ASK1; polyclonal rabbit anti-human; dilution, 1:1,000; catalog no., 3762; Cell Signaling Technology Inc., Danvers, MA, USA), anti-thioredoxin binding protein 2 (TBP-2; monoclonal mouse anti-human; dilution, 1:1,000; catalog no., K02053; MBL International Co., Woburn, MA, USA) and anti-histone deacetylase 1 (HDAC1; polyclonal rabbit anti-human; dilution, 1:1,000; catalog no., 2062; Cell Signaling Technology Inc.). Subsequently, the membranes were incubated with a horseradish peroxidase-labeled secondary antibody (dilution, 1:2,000; Santa Cruz Biotechnology, Inc., Dallas, TX, USA). Anti- $\beta$-actin monoclonal antibody (Santa Cruz Biotechnology, Inc.) was used as an endogenous control. The results were analyzed by AlphaView software version 3.3.0.0 (ProteinSimple, Santa Clara, CA, USA). The integral optical density (IOD) of each band was determined. The relative protein levels were used to evaluate the differences between the solanine-treated group and the control group, using the following equation: The relative protein level $=$ IOD ratio between the target gene product bands and the $\beta$-actin protein bands in the solanine-treated group / IOD ratio between the target gene product bands and the $\beta$-actin protein bands in the control group.

Annexin V-fluorescein isothiocyanate (FITC)/propidium iodide (PI) analysis. The HepG2 cells were harvested $48 \mathrm{~h}$ after solanine treatment. The percentage of cells undergoing apoptosis was detected using a FITC Annexin V Apoptosis Detection kit II (BD Pharmingen, San Diego, CA, USA) and flow cytometry (BD LSR II Flow Cytometer).

Cell counting and morphological observation. The cells were harvested at the logarithmic growth phase and counted using a Countess II FL Automated Cell Counter (Invitrogen; Thermo Fisher Scientific, Inc.). A total of $4 \times 10^{4}$ cells were added to each well of a 6 -well plate containing $2 \mathrm{ml}$ medium, and the plate was placed into a $5 \% \mathrm{CO}_{2}$ humidified incubator at $37^{\circ} \mathrm{C}$ overnight (16-24 h). Subsequently, DMSO, $2 \mathrm{mg} / \mathrm{ml}$ solanine or $0.5 \mathrm{mg} / \mathrm{ml}$ camptothecin was added to the cells and incubated for an additional 24-48 h. The morphological alterations in the cells were observed using an optical microscope (Olympus IX70 Inverted Microscope; Olympus Corporation, Tokyo, Japan) following staining with Wright's stain (Sangon Biotech Co., Ltd.).

Statistical analysis. All experiments were repeated three times independently. The results are presented as the 
A

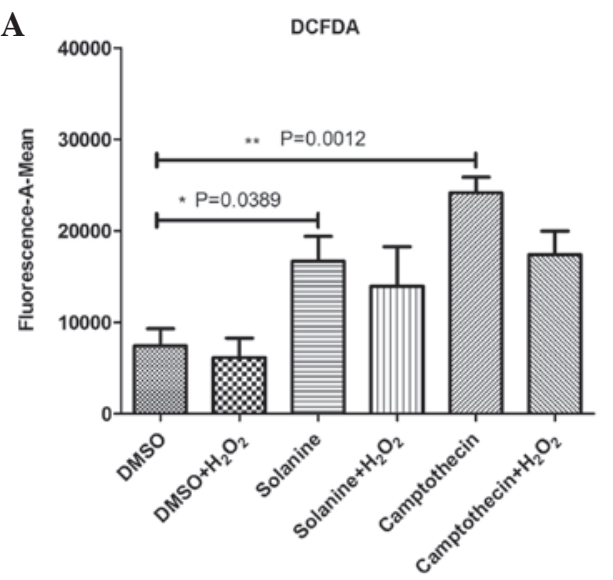

C

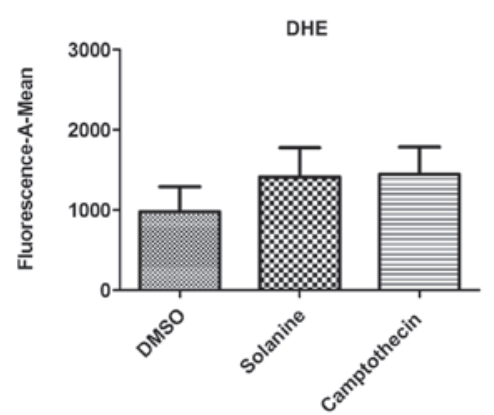

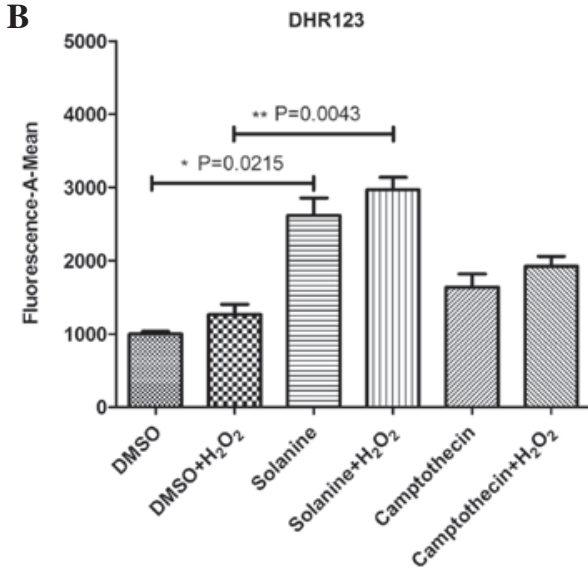

D

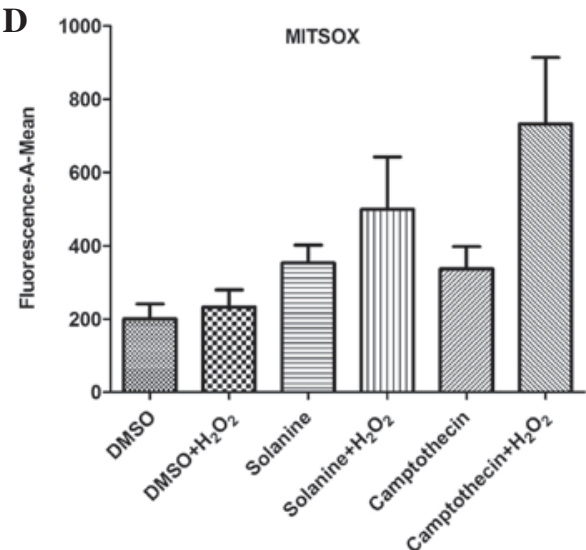

Figure 1. Various probes were used to detect reactive oxygen species produced by solanine-induced human hepatocellular carcinoma HepG2 cells. (A) DCFDA probe was used to detect $\mathrm{OH}^{-}$and $\mathrm{H}_{2} \mathrm{O}_{2}$ in the cytoplasm, (B) DHR 123 probe was used to detect $\mathrm{OH}^{-}$and $\mathrm{H}_{2} \mathrm{O}_{2}$ in the mitochondria, (C) DHE probe was used to detect $\mathrm{O}_{2}^{-}$in the cytoplasm, and (D) MITSOX probe was used to detect $\mathrm{O}_{2}^{-}$in the mitochondria. DCFDA, 2',7'-dichlorofluorescin diacetate; DHR 123, dihydrorhodamine 123; DHE, dihydroethidium; MITSOX, MitoSOX ${ }^{\mathrm{TM}}$ Red Mitochondrial Superoxide Indicator; $\mathrm{OH}^{-}$, hydroxyl radical; $\mathrm{H}_{2} \mathrm{O}_{2}$, hydrogen peroxide; $\mathrm{O}_{2}{ }^{-}$, superoxide anion; DMSO, dimethyl sulfoxide.

mean \pm standard deviation. One-way analysis of variance was performed using SPSS version 11.0 software (SPSS, Inc., Chicago, IL, USA) in order to detect significant differences in measured variables between groups. $\mathrm{P}<0.05$ was considered to indicate a statistically significant difference.

\section{Results}

Solanine induces the production of ROS in the cytoplasm and mitochondria of HepG2 cells. The HepG2 cells were treated with various concentrations of $\mathrm{H}_{2} \mathrm{O}_{2}$ for the same amount of time $(30 \mathrm{~min})$, and separately with the same concentration $(0.5 \mathrm{mmol} / \mathrm{l})$ for various time periods. The cells were incubated with DCFDA for $30 \mathrm{~min}$. The results demonstrated that the optimal concentration and effective time for $\mathrm{H}_{2} \mathrm{O}_{2}$ stimulation of the cells were $0.5 \mathrm{mM}$ and $30 \mathrm{~min}$, respectively.

Following solanine pretreatment, the HepG2 cells were stimulated by $\mathrm{H}_{2} \mathrm{O}_{2}$ according to the pretested parameters, and various probes were used that were specific to certain ROS. The results revealed that ROS probes DCFDA and DHR 123 detected abundant ROS, including hydroxyl radical $\left(\mathrm{OH}^{-}\right)$and $\mathrm{H}_{2} \mathrm{O}_{2}$, in the cytoplasm and mitochondria of the HepG2 cells pretreated with solanine compared with the control group [DCFDA $(n=5), P=0.0389$; DHR $123(n=5), P=0.0215]$. The amount of ROS produced by the solanine-treated cells was decreased compared with the ROS produced by camptothecin-treated cells, which was observed using the DCFDA probe. By contrast, the amount of ROS produced by the solanine-treated cells was increased compared with the ROS produced by the camptothecin-treated cells, as determined using the DHR123 probe. This suggests that ROS production in various cellular locations may be by differential mechanisms. Increased levels of ROS production were also observed post $-\mathrm{H}_{2} \mathrm{O}_{2}$ stimulation, as detected by the DHR123 probe $(\mathrm{n}=5$; $\mathrm{P}=0.0043)$. Superoxide anion $\left(\mathrm{O}_{2}^{-}\right) \mathrm{ROS}$, which was generated by solanine pretreatment, was also detected by $\mathrm{O}_{2}^{-}$-specific DHE and MITSOX probes. However, there was no significant difference between the solanine-treated and control groups [DHE ( $n=5), P=0.606$; MITSOX (n=5), P=0.107] (Fig. 1).

Solanine induces the upregulation of ASK1 and TBP-2, and the downregulation of $H D A C 1$. It has previously been suggested that ASK1 is an important protein involved in regulating apoptosis (22). Another apoptosis-associated protein is TBP-2, also termed vitamin D-upregulated protein 1, which effectively combines with thioredoxin, eventually leading to cellular apoptosis (23). The increased expression of HDAC1 increases the proliferation of tumor cells and alters the extracellular matrix; therefore, significantly promoting tumor cell migration and aggression (24). In addition, HDAC1 removes 
A
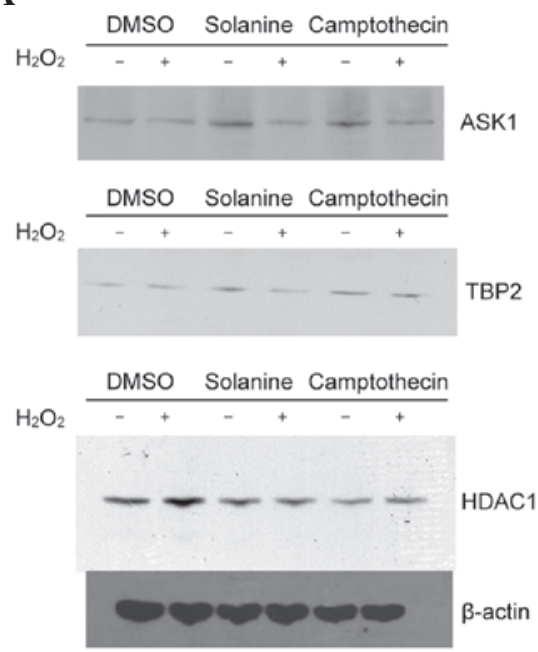
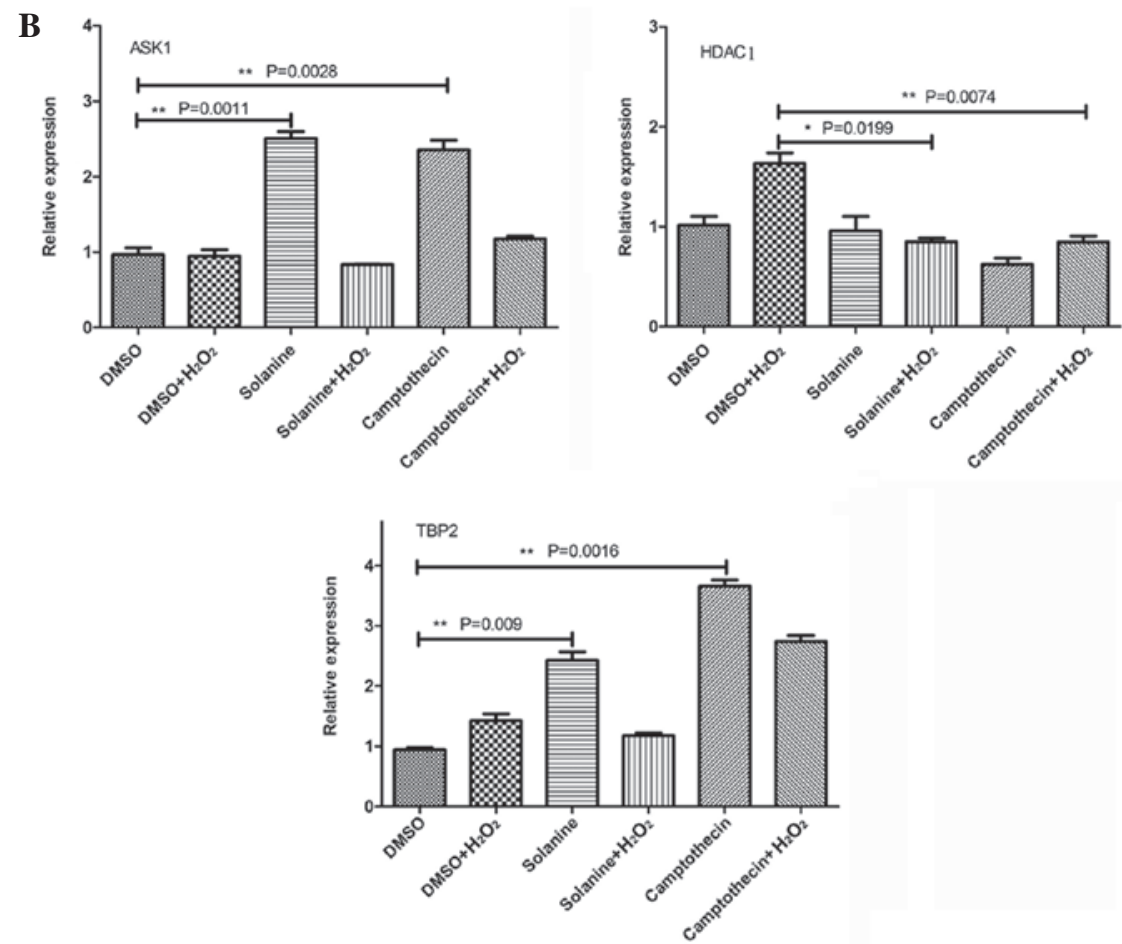

Figure 2. Western blot analysis of ASK1, TBP-2 and HDAC1 expression in human hepatocellular carcinoma HepG2 cells. (A) A representative western blot analysis. (B) Relative protein expression levels of ASK1, TBP-2 and HDAC1 were assessed by calculating the IOD values. IOD values were normalized to those of $\beta$-actin protein. ${ }^{* *} \mathrm{P}<0.001$. Results are representative of 3 experiments. ASK-1, apoptosis signal-regulating kinase 1; TBP-2, thioredoxin binding protein 2 ; $\mathrm{HDAC1}$, histone deacetylase 1; IOD, integral optical density; DMSO, dimethyl sulfoxide; $\mathrm{H}_{2} \mathrm{O}_{2}$, hydrogen peroxide.
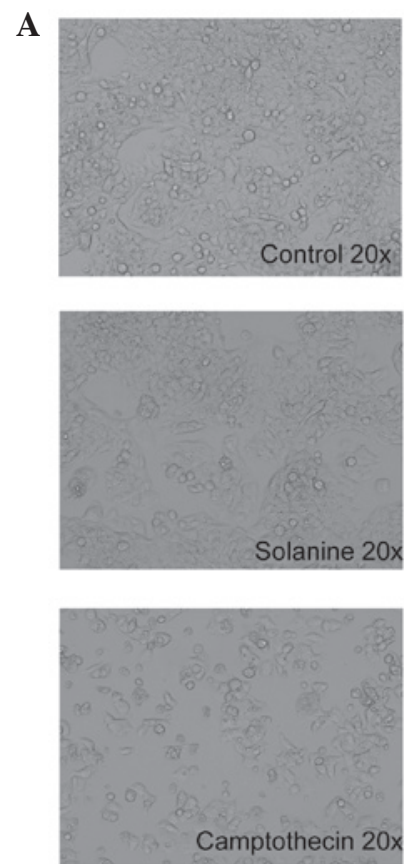
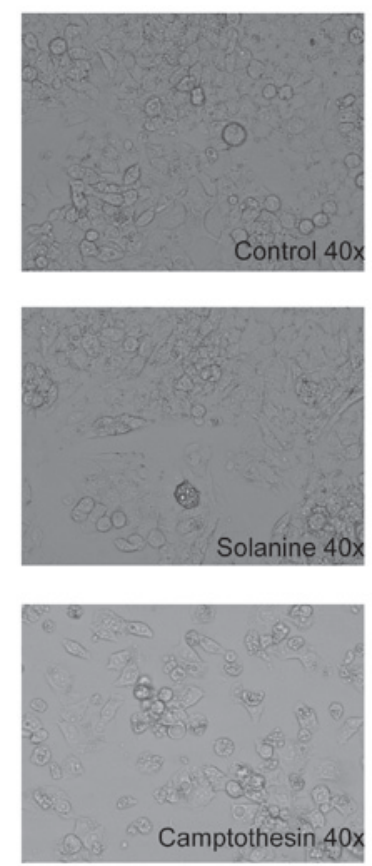

B

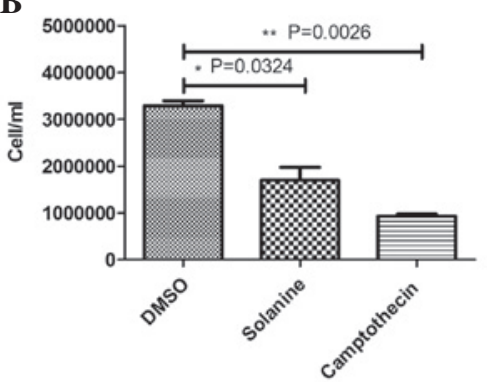

Figure 3. (A) The morphology alterations observed in human hepatocellular carcinoma HepG2 cells following treatment with solanine and camptothecin. (B) Quantification of cell counting. DMSO, dimethyl sulfoxide.

the acetyl-groups on histones, a more advanced chromosome structure, and inhibits basic transcription complex assembly; therefore, inhibiting transcription (25). The present results demonstrated that solanine and camptothecin increased the expression of ASK1 and TBP-2, but reduced the expression of HDAC1 (Fig. 2).
Solanine significantly inhibits the growth of HepG2 cells and triggers cell apoptosis. Next, the present study investigated the effect of solanine on the growth and apoptosis of the HepG2 cells. As revealed by Fig. 3A, the HepG2 cells treated with solanine exhibited notable morphological alterations in contrast to the control cells, which exhibited no alterations in 
$\mathbf{A}$

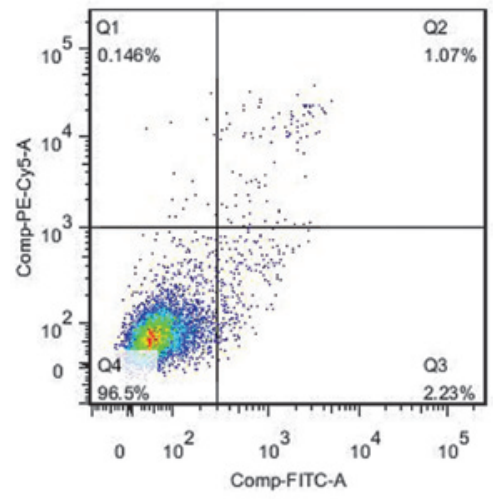

C

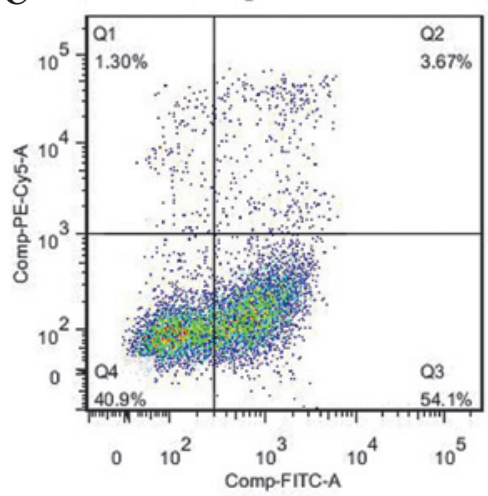

B

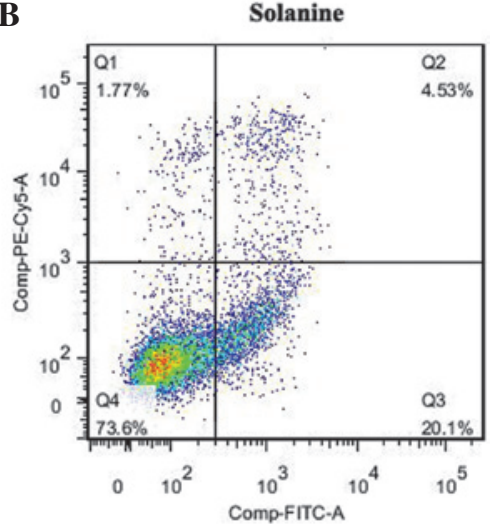

D

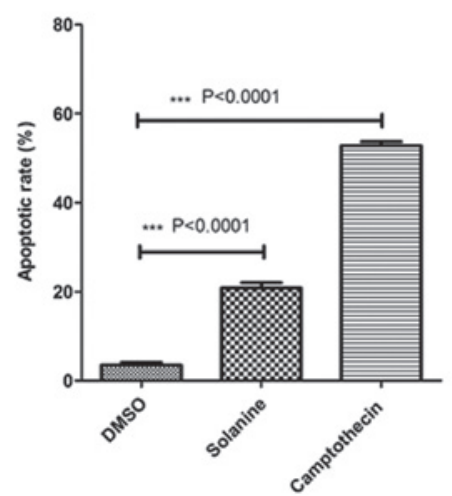

Figure 4. Cells treated with solanine or camptothecin promote the apoptosis of human hepatocellular carcinoma HepG2 cells. (A-C) Annexin V-FITC/propidium iodide staining and flow cytometric analysis of cells undergoing apoptosis with (A) DMSO, (B) solanine and (C) camptothecin treatment. The lower-right quadrant of each plot indicates early apoptotic cells. (D) Flow cytometry analysis of the percentage of apoptotic cells in each treatment group. ${ }^{* * *} \mathrm{P}<0.0001$. DMSO, dimethyl sulfoxide; FITC, fluorescein isothiocyanate.

morphology. The solanine-treated cells exhibited numerous cytoplasmic vacuoles, and the cells were round, shrunken and detached. The number of cells was significantly decreased in the solanine-treated $(\mathrm{n}=3 ; \mathrm{P}=0.0324)$ and camptothecin-treated groups $(\mathrm{n}=3 ; \mathrm{P}=0.0026)$ compared with the control group (Fig. 3B).

Consistent with the cell counting results, flow cytometry analysis confirmed that there was an increased percentage of cells undergoing apoptosis in the solanine and camptothecin-treated groups compared with the control group (Fig. 4). This indicates that following treatment with solanine, the reduced cell growth observed may be due to enhanced cellular apoptosis.

\section{Discussion}

ROS, including $\mathrm{O}_{2}^{-}, \mathrm{H}_{2} \mathrm{O}_{2}$ and $\mathrm{OH}^{-}$, are products of aerobic respiration in eukaryotic cells. ROS have a cytotoxic effect and are also intracellular signal transduction and gene expression regulation molecules, with key roles in the regulation of cell growth, survival and apoptosis (26-28). The mitochondria of a eukaryotic cell are the main site for the production of ROS, and a large amount of ROS may be produced in the process of oxidative phosphorylation. The impact of reactive oxygen on the mitochondria results in the dissipation of the mitochondrial membrane potential, the release of cytochrome $c$ and causes the mitochondrial membrane permeability transition pore
(PTP) to open (29). A variety of proapoptotic signals, including physical damage, radiation, chemotherapy, excitatory amino acids and death ligands, may cause an increase in cellular endogenous or exogenous ROS, or alter the redox equilibrium, and these signals may trigger cellular apoptosis. Once an apoptotic pathway is activated, an increase in the expression of ROS may accelerate the apoptosis process (30-32). Therefore, the release of ROS and the process of apoptosis are mutually affected.

In recent years, solanine has become notable due to its antitumor properties. The main components of solanine that have these antitumor properties are the alkaloids, which lead to cytotoxicity and anti-nuclear splitting in tumor cells (33). Previous studies have demonstrated that solanine has a clear cytotoxic effect on human HepG2 cells through the direct inhibition of the activity of matrix metalloproteinase (MMP)-2 and MMP-9 and tumor angiogenesis; therefore, inhibiting tumor metastasis $(34,35)$. In addition, solanine reduces the mitochondrial membrane potential, by increasing the opening of the PTP. Opening of the PTP leads to an increase in calcium ions, which initiates cell apoptosis resulting in an antitumor effect (36).

The present results demonstrated that solanine induces HepG2 cells to significantly produce ROS, including $\mathrm{OH}^{-}$and $\mathrm{H}_{2} \mathrm{O}_{2}$, in the cytoplasm and mitochondria of the cell, to a similar level as the positive control, compared with the negative control $(\mathrm{P}<0.05)$. In the present study, the specific probes 
targeting differential-localized ROS identified that ROS components remained in the cytoplasm and mitochondria of the cells; however, the main location for the production of ROS was observed to be in the mitochondria. The ROS produced in the mitochondria may directly diffuse to the cytoplasm due to the increasing permeability of the mitochondrial membrane. However, the increased expression of ROS was not detected by the DCFDA and DHR 123 probes, specific for $\mathrm{OH}^{-}$and $\mathrm{H}_{2} \mathrm{O}_{2}$, respectively, post $-\mathrm{H}_{2} \mathrm{O}_{2}$ stimulation. This may be due to the following possible explanations: Apoptosis, induced by antitumor drugs, may have a different apoptosis response compared with non-chemotherapy-induced apoptosis due to cell cycle sensitivity $(37,38)$. The permeability of the membrane of the HepG2 cells remains relatively high when exposed to antitumor drugs, indicating a potential possibility of an intracellular pattern of diffusion as $\mathrm{H}_{2} \mathrm{O}_{2}$ enters the cell. Previous findings have demonstrated that growth of tumor cells may be inhibited when they are pretreated with chemotherapeutics. Subsequent simulation by $\mathrm{H}_{2} \mathrm{O}_{2}$ may therefore result in tumor shedding and necrosis, which has a lower fluorescence signal. In addition, the present study identified that there was no difference in the expression of $\mathrm{O}_{2}^{-}$with specific probes DHE and MITSOX in the solanine, camptothecin and control cell groups $(\mathrm{P}>0.05)$. This suggests that solanine may induce the cytoplasm and mitochondria of $\mathrm{HepG} 2$ cells to produce ROS, which consists of $\mathrm{OH}^{-}$and $\mathrm{H}_{2} \mathrm{O}_{2}$, but not $\mathrm{O}_{2}^{-}$. Therefore, the effects of solanine on tumor cells was generated by the production of $\mathrm{OH}^{-}$and $\mathrm{H}_{2} \mathrm{O}_{2}$.

In addition, the present study investigated the alterations in the expression of certain apoptosis- and proliferation-associated proteins in solanine-induced cellular apoptosis. The present results demonstrated that an increase in the expression levels of ASK1 and TBP-2, which activate downstream signaling pathways, including c-Jun N-terminal kinases (JNK) and p38 mitogen-activated protein kinases (p38), may be the main mechanism through which the HepG2 cells underwent apoptosis. Solanine also significantly inhibited the expression of the proliferation-associated protein $\mathrm{HDAC}$, which is another possible mechanism of the antitumor effects of solanine treatment. To additionally elucidate the molecular mechanisms of solanine-induced cellular apoptosis, the specific inhibition of mitochondrial $\mathrm{O}_{2}^{-}$should be performed to investigate whether solanine-induced apoptosis is associated with mitochondrial $\mathrm{O}_{2}$. Studies are ongoing to investigate this hypothesis.

In conclusion, solanine induces $\mathrm{HepG} 2$ cells to produce ROS, mainly $\mathrm{OH}^{-}$and $\mathrm{H}_{2} \mathrm{O}_{2}$, and increases the expression and activity of the apoptosis-associated proteins ASK1 and TBP-2, which activate downstream signaling pathways, including JNK and p38, eventually leading to cell apoptosis. Therefore, solanine is a potential anticancer drug, which may have a clinical application in the future.

\section{Acknowledgements}

The present study was partially supported by the Administration of Traditional Chinese Medicine of Zhejiang Province (grant no. 2011ZA046), the Major Program of Science and Technology Bureau of Zhejiang Province (grant no. 2013C37002) and the National Natural Science Foundation of China (grant no. 81401319). The abstract was presented at the International Liver Transplantation Society 21st Annual International Congress July 8-11 2015 in Chicago (IL, USA) and published as abstract no. P-110 on the Abstracts2View ${ }^{\mathrm{TM}}$ Portal (http://www.abstracts2view.com/ilts/).

\section{References}

1. Shariff MI, Cox IJ, Gomaa AI, Khan SA, Gedroyc W and Taylor-Robinson SD: Hepatocellular carcinoma: Current trends in worldwide epidemiology, risk factors, diagnosis and therapeutics. Expert Rev Gastroenterol Hepatol 3: 353-367, 2009.

2. Altekruse SF, McGlynn KA and Reichman ME: Hepatocellular carcinoma incidence, mortality, and survival trends in the United States from 1975 to 2005. J Clin Oncol 27: 1485-1491, 2009.

3. Rampone B, Schiavone B, Martino A, Viviano C and Confuorto G: Current management strategy of hepatocellular carcinoma. World J Gastroenterol 15: 3210-3216, 2009.

4. Stefaniuk P, Cianciara J and Wiercinska-Drapalo A: Present and future possibilities for early diagnosis of hepatocellular carcinoma. World J Gastroenterol 16: 418-424, 2010.

5. Wang X, Wang N, Cheung F, Lao L, Li C and Feng Y: Chinese medicines for prevention and treatment of human hepatocellular carcinoma: Current progress on pharmacological actions and mechanisms. J Integr Med. 13: 142-164, 2015.

6. Kodamatani H, Saito K, Niina N, Yamazaki S and Tanaka Y: Simple and sensitive method for determination of glycoalkaloids in potato tubers by high-performance liquid chromatography with chemiluminescence detection. J Chromatogr A 1100: 26-31, 2005.

7. Friedman M: Potato glycoalkaloids and metabolites: Roles in the plant and in the diet. J Agric Food Chem 54: 8655-8681, 2006.

8. Bodart P and Noirfalise A: Glycoalkaloids in potatoes. Rev Med Liege 58: 25-32, 2003 (In French).

9. Shindo T, Ushiyama H, Kan K, Yasuda K and Saito K: Contents and its change during storage of alpha-solanine and alpha-chaconine in potatoes. Shokuhin Eiseigaku Zasshi 45: 277-282, 2004 (In Japanese).

10. Zywicki B, Catchpole G, Draper J and Fiehn O: Comparison of rapid liquid chromatography-electrospray ionization-tandem mass spectrometry methods for determination of glycoalkaloids in transgenic field-grown potatoes. Anal Biochem 336: 178-186, 2005.

11. Korpan YI, Nazarenko EA, Skryshevskaya IV, Martelet C, Jaffrezic-Renault N and El'skaya AV: Potato glycoalkaloids: True safety or false sense of security? Trends Biotechnol 22: 147-151, 2004.

12. Glossman-Mitnik D: CHIH-DFT determination of the molecular structure and infrared and ultraviolet spectra of gamma-solanine. Spectrochim Acta A Mol Biomol Spectrosc 66: 208-211, 2007.

13. Stobiecki M, Matysiak-Kata I, Frański R, Skała J and Szopa J: Monitoring changes in anthocyanin and steroid alkaloid glycoside content in lines of transgenic potato plants using liquid chromatography/mass spectrometry. Phytochemistry 62: 959-969, 2003

14. Wang S, Panter KE, Gaffield W, Evans RC and Bunch TD: Effects of steroidal glycoalkaloids from potatoes (Solanum tuberosum) on in vitro bovine embryo development. Anim Reprod Sci 85: 243-250, 2005.

15. Ji YB (ed): Antitumor effects in traditional Chinese medicine. In: Pharmacological Action, Application of Available Composition of Traditional Chinese Medicine. 1st edition. Heilongjiang Science and Technology Press, Harbin, Heilongjiang, pp433, 1995 (In Chinese).

16. Son YO, Kim J, Lim JC, Chung Y, Chung GH and Lee JC: Ripe fruit of Solanum nigrum $L$. inhibits cell growth and induces apoptosis in MCF-7 cells. Food Chem Toxicol 41: 1421-1428, 2003.

17. An L, Tang JT, Liu XM and Gao NN: Research progress on mechanism of anti-tumor effect of Solanum nigrum. Zhongguo Zhong Yao Za Zhi 31: 1225-1226, 2006 (In Chinese).

18. Ji YB, Gao SY, Ji CF and Zou X: Induction of apoptosis in HepG2 cells by solanine and Bcl-2 protein. J Ethnopharmacol 115: 194-202, 2008.

19. Macho A, Hirsch T, Marzo I, Marchetti P, Dallaporta B, Susin SA, Zamzami N and Kroemer G: Glutathione depletion is an early and calcium elevation is a late event of thymocyte apoptosis. J Immunol 158: 4612-4619, 1997. 
20. Gao SY, Wang QJ and Ji YB: Effect of solanine on the membrane potential of mitochondria in HepG2 cells and [Ca2+]i in the cells. WorId J Gastroenterol 12: 3359-3367, 2006.

21. Eom KS, Kim HJ, So HS, Park R and Kim TY: Berberine-induced apoptosis in human glioblastoma T98G cells is mediated by endoplasmic reticulum stress accompanying reactive oxygen species and mitochondrial dysfunction. Biol Pharm Bull 33 1644-1649, 2010.

22. Sinha K, Das J, Pal PB and Sil PC: Oxidative stress: The mitochondria-dependent and mitochondria-independent pathways of apoptosis. Arch Toxicol 87: 1157-1180, 2013.

23. Hashiguchi K, Tsuchiya H, Tomita A, Ueda C, Akechi Y Sakabe T, Kurimasa A, Nozaki M, Yamada T, Tsuchida S and Shiota G: Involvement of ETS1 in thioredoxin-binding protein 2 transcription induced by a synthetic retinoid CD437 in human osteosarcoma cells. Biochem Biophys Res Commun 391: 621-626, 2010.

24. Bouchain G and Delorme D: Novel hydroxamate and anilide derivatives as potent histone deacetylase inhibitors: Synthesis and antiproliferative evaluation. Curr Med Chem 10: 2359-2372, 2003.

25. Phi van DK , Mühlbauer E and Phi-van L: Histone deacetylase HDAC1 downregulates transcription of the serotonin transporter (5-HTT) gene in tumor cells. Biochim Biophys Acta 1849: 909-918, 2015.

26. Lee WL, Huang JY and Shyur LF: Phytoagents for cancer management: Regulation of nucleic acid oxidation, ROS and related mechanisms. Oxid Med Cell Longev 2013: 925804, 2013.

27. Zou Y, Yang J, Liu X and Yuan J: Relationship between reactive oxygen species and apoptosis in HepG2 cells induced by sodium selenite. Wei Sheng Yan Jiu 36: 272-274, 2007 (In Chinese).

28. Wu XD, Jin ZX, Wan CL and Jin R: Effect of herba agrimoniae in apoptosis of human hepatoma cell line HepG2 cells research. Zhong Guo Zhong Yi Yao Zi Xun 2: 8, 2010 (In Chinese).
29. Chen WQ, Shen W and Shen DM: The changes of ROS and mitochondria membrane potential in HepG2 cells on the pressure of cisplatin. Zhonghua Gan Zang Bing Za Zhi 13: 531-533, 2005 (In Chinese)

30. Hu YZ, Dong YG, Zhai YF, Lu JH, Wu MX, Zhou Y and He ZY: Effect of simvastatin on homocysteine - induced endothelial dysfunction and inflammatory response and its molecular mechanisms. Zhongguo Bingli Shengli Zazhi 8: 1594-1598, 2005 (In Chinese).

31. Djordjević VB: Free radicals in cell biology. Int Rev Cytol 237: 57-89, 2004

32. Closa D and Folch-Puy E: Oxygen free radicals and the systemic inflammatory response. IUBMB Life 56: 185-191, 2004.

33. Zhao XQ: Solanum nigrum compound syrup-induced hepatocyte apoptosis in murine I-122 mechanism. Liaoning Zhongyi Zazhi 9: 974-975, 2005 (In Chinese).

34. Lu MK, Shih YW, Chang Chien TT, Fang LH, Huang HC and Chen PS: $\alpha$-Solanine inhibits human melanoma cell migration and invasion by reducing matrix metalloproteinase-2/9 activities. Biol Pharm Bull 33: 1685-1691, 2010.

35. Lu MK, Chen PH, Shih YW, Chang YT, Huang ET, Liu CR and Chen PS: Alpha-chaconine inhibits angiogenesis in vitro by reducing matrix metalloproteinase-2. Biol Pharm Bull 33: 622-630, 2010.

36. Lépine S, Sulpice JC and Giraud F: Signaling pathways involved in glucocorticoid-induced apoptosis of thymocytes. Crit Rev Immunol 25: 263-288, 2005.

37. Tang B, Du J, Wang J, Tan G, Gao Z, Wang Z and Wang L: Alpinetin suppresses proliferation of human hepatoma cells by the activation of MKK7 and elevates sensitization to cis-diammined dichloridoplatium. Oncol Rep 27: 1090-1096, 2012.

38. Al-Qubaisi M, Rozita R, Yeap SK, Omar AR, Ali AM and Alitheen NB: Selective cytotoxicity of goniothalamin against hepatoblastoma HepG2 cells. Molecules 16: 2944-2959, 2011. 